\section{Construcción de la base gráfica para un sistema de información y gestión del patrimonio arquitectónico: Casa de Hylas}

\section{Setting-up a graphical basis for an information and management system of architectural heritage: House Hylas}

Roque Angulo Fornos*

Universidad de Sevilla

\section{Resumen}

La experiencia profesional y el contacto con especialistas en la materia ponen de manifiesto una problemática acuciante en el terreno del conocimiento y gestión del patrimonio arquitectónico: la tendencia a la dispersión de la información obtenida desde los distintos ámbitos -administración, comunidad científica y profesionales de la arquitectura-y disciplinas intervinientes -arqueólogos, historiadores, arquitectos, etc.-, generando graves situaciones de pérdidas o duplicidades de datos. Esa realidad ha revertido en la falta de eficiencia en la programación y ejecución de las diversas actividades de mantenimiento, conservación e intervención en estas arquitecturas, así como en el despilfarro de importantes labores investigadoras que dificulta la divulgación y, por tanto, el conocimiento de las mismas. Como posible solución a dicha problemática este artículo describe una experiencia que pretende establecer las bases para la construcción de una herramienta que, basada en un modelo infográfico, sea capaz de contener y gestionar toda la información generada sobre un monumento histórico, facilitando relaciones de transversalidad entre los distintos análisis que abordan el conocimiento del edificio. En este caso, el análisis de los aspectos constructivos y de conservación de uno de los inmuebles del Conjunto Arqueológico de Itálica es el que ha aportado contenido a esta herramienta todavía en estado de gestación, estableciendo así los conocimientos básicos para su gestión y conservación.

Palabras clave: arqueología, arquitectura, patrimonio, levantamiento, fotogrametría, modelado, información, BIM, Itálica.

\begin{abstract}
Professional experience and contact with experts reveal a pressing problem in the field of knowledge and management of architectural heritage: the tendency to scatter the information obtained from the different areas -administration, scientific community and professionals of architecture- and disciplines involved -archaeologists, historians, architects, etc.-, causing serious problems of data loss or duplication. That reality has produced lack of efficiency in planning and implementing the various activities of maintenance and intervention in these architectures, as well as wastage of important investigative work. Such circumstances obstruct disclosure and, therefore, knowledge of heritage. As a possible solution to that problem, this article describes an experience that aims to lay the groundwork for building a tool that, based on computer models, is able to contain and manage the information generated about a historical monument, facilitating cross-cutting relationships between different analysis that address the knowledge of the building. In this case, the analysis of the construction and conservation of one of the buildings of the archaeological site of Italica forms the data base of this tool still in gestation, thus establishing the basic knowledge for its management and conservation.
\end{abstract}

Keywords: archeology, architecture, heritage, survey, photogrammetry, modeling, information, BIM, Itálica.

\section{ANTECEDENTES}

Este trabajo se enmarca dentro de la línea de investigación Modelos Infográficos para la Gestión de la Información Arquitectónica del Grupo PAI HUM799¹, la cual parte de dos consideraciones básicas: por un lado, que la complejidad de los procesos de transformación en el tiempo que dan lugar a la arquitectura de carácter patrimonial deben ser registrados y valorados para formar parte indispensable de su conocimiento; y por otro lado, que toda intervención en dicho patrimonio se basa en una interpretación desde una posición determinada, la cual debe poder ser revisable y reformulada con objeto de evitar pérdidas de información. Así, el conocimiento del patrimonio arquitectónico debe desvincularse necesariamente de tendencias enfocadas hacia la dispersión de la información obtenida desde distintos ámbitos y disciplinas, generando situaciones de solapamientos y duplicidades en la obtención de datos e incoherencias en las conclusiones derivadas de los correspondientes análisis, y buscar, por el contrario, la interconexión entre las distintas direcciones a través de modelos dinámicos de conocimiento sometidos a una continua actualización.

Las últimas décadas han potenciado la consideración del objeto arquitectónico como documento en sí mismo, contenedor de una gran cantidad de información necesaria para el conocimiento de su realidad física en todos los aspectos posibles y de las circunstancias históricas y culturales que lo han generado y transformado. Dicha consideración es razón suficiente para su estricto registro, evitando así la destrucción o alteración de indicios cuyo significado pueda ser traducido en el futuro.

En el ámbito arqueológico, dicho registro viene precedido por una importante tradición gráfica basada en la realización de dibujos en los que se buscaba plasmar de forma objetiva la mayor cantidad de información posible reproduciendo los principales atributos de la realidad física. La creación de la Escuela de Arquitectura de Madrid en 1846, que asume el papel de la Real Academia de San Fernando en la enseñanza de esta disciplina tras la reforma de las Bellas Artes, impulsó en España el estudio de sus monumentos y su conocimiento directo a través de excursiones —englobando tanto la arquitectura más o menos transformada como los yacimientos arqueológicos que en esa época empezaban a considerarse- que supusieron el germen de los inacabados volúmenes de Monumentos

\footnotetext{
Grupo de investigación HUM799 (Universidad de Sevilla): Estrategias de Conocimiento Patrimonial. Responsable: Dr. D. Francisco Pinto Puerto. http:// grupo.us.es/ecphum799/.
} 


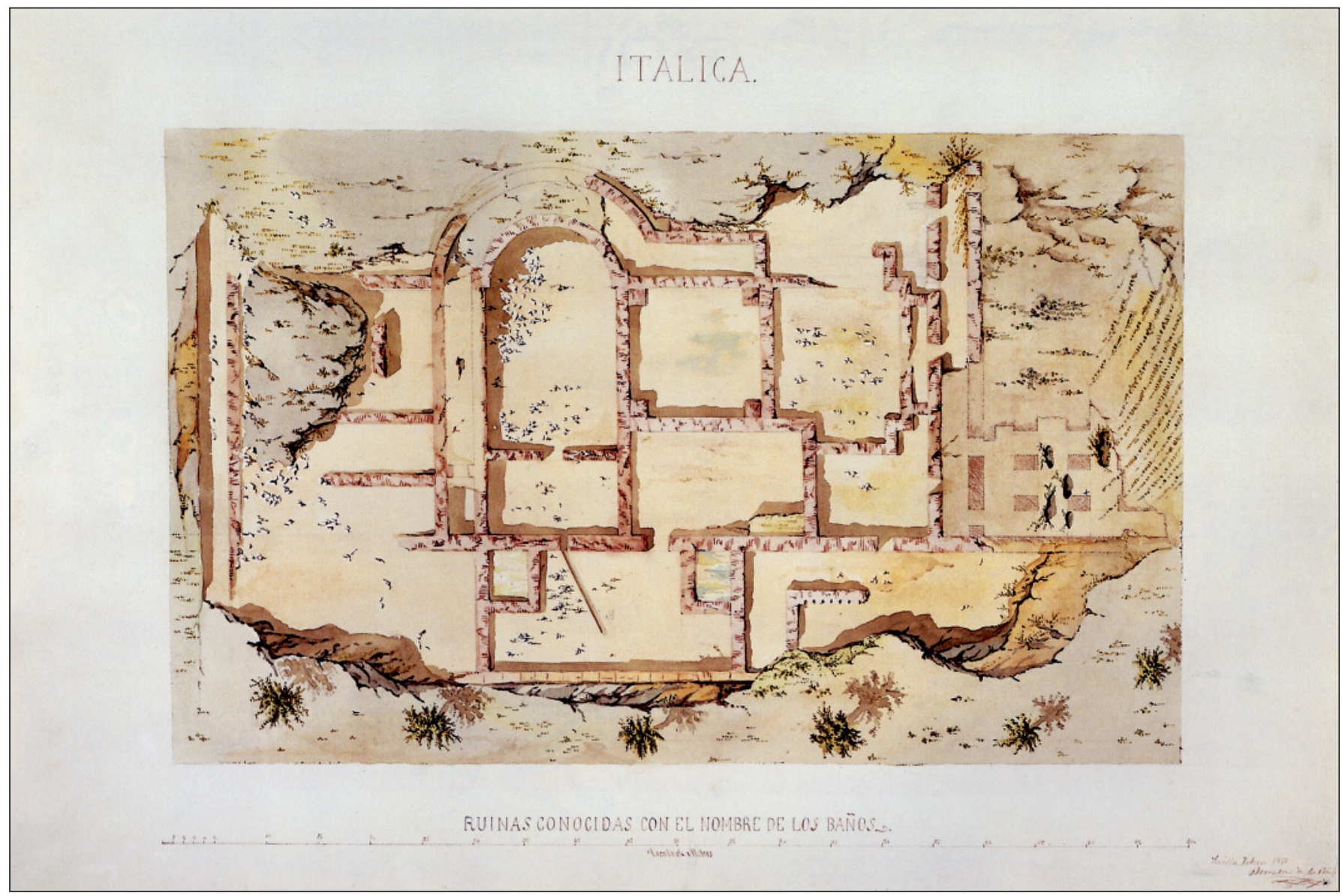

Fig. 1. «Ruinas conocidas con el nombre de los baños». Demetrio de los Ríos. Sevilla, febrero de 1858. (Fernández Gómez, 1998: Lámina 7. Página 139)

Arquitectónicos de España entre 1859 y 1887 (Esteban 2007, p. 24). Demetrio de los Ríos - hermano de José Amador de los Ríos, autor de algunos textos de Monumentos... y acérrimo defensor de las ruinas de Itálica- fue el impulsor de las primeras excavaciones en dicho yacimiento $^{2}$ y autor de los levantamientos gráficos que las documentaron (Fig.1). A pesar de la gran calidad gráfica y artística que estos dibujos atesoraban, el registro de la ruina siempre quedaba mermado por el inevitable obstáculo de tener que traducir las tres dimensiones de su realidad a las dos dimensiones del soporte tradicional. Ese condicionante ha sido constante hasta que los avances tecnológicos han propiciado la aparición de nuevas herramientas que transforman nuestros modos de registrar la realidad, y por tanto de conocerla, y es ahí donde incide este trabajo.

Por otro lado, el contenido de este artículo pretende dar respuesta a los problemas detectados durante el desarrollo de unos trabajos realizados para el Conjunto Arqueológico de Itálica. Este yacimiento fue declarado monumen-

${ }^{2}$ Caballos, Marín y Rodríguez (1999), p.46. to nacional en 1912 y, coincidiendo con los cien años de este reconocimiento, la Consejería de Cultura de la Junta de Andalucía pretendía completar en el año 2012 la elaboración de su Plan Director donde quedara recogido el estado actual del yacimiento y su planificación futura. Este Plan Director fue presentado en forma de avance el año 2011, estando en la actualidad en fase de revisión ${ }^{3}$. Con tal motivo, el Conjunto Arqueológico de Itálica organizó una serie de grupos de trabajos multidisciplinares (arqueólogos, restauradores, museógrafos, arquitectos, urbanistas y paisajistas, etc.) entre los años 2009 y 2011 que desarrollaran un diagnóstico de la situación actual, y una previsión de acciones de conservación, mantenimiento y difusión imprescindibles. El último informe sobre el estado de conservación del conjunto fue realizado por Juan de Mata Carriazo y Francisco Collantes de Terán en 1933, y por entonces no tenía ni la amplitud ni la complejidad del actual ${ }^{4}$. Este dos-

${ }^{3}$ Rodríguez de Guzmán Sánchez (2011).

${ }^{4}$ Collantes de Terán, F. Trabajos en Itálica. AEA 24,1940-41, pp. 235-238. citado en Caballos, Marín y Rodríguez (1999) p. 48; también en Luzón (1979) p. 19. 
sier, que aún está inédito - formado por cerca de 800 documentos entre los que se encuentran inventarios epigráficos, croquis, y dibujos - es representativo de la situación que se pretende solucionar con el actual Plan Director, y especialmente con el trabajo que se nos encomendó.

$\mathrm{Al}$ equipo del que formé parte , en este caso arquitectos, se nos encargó el estudio cualitativo y cuantitativo de las principales patologías que presentaban actualmente los restos arquitectónicos conservados, así como las acciones de consolidación y/o intervención que debían considerarse y su grado de urgencia. Además se nos solicitaba la racionalización de la información gráfica existente sobre el Conjunto, completando los levantamientos en aquellas zonas en las que se carecía de ellos, adaptándola a los requerimientos que demandaban sus usuarios —básicamente arqueólogos, arquitectos, restauradores e investigadores de bienes muebles - y prepararla para una futura consulta generalizada a distintos niveles.

La aportación que aquí se expone surge inicialmente como respuesta a una serie de carencias detectadas en el desarrollo de este último trabajo de análisis y racionalización de la información gráfica, para terminar planteando soluciones a otras necesidades demandadas desde los otros dos trabajos acometidos de diagnóstico y propuestas de conservación.

Nos enfrentábamos a un problema tan amplio y complejo como toda una ciudad organizada en edificios públicos, semipúblicos, privados, espacios e infraestructuras urbanas de las que se conservan no sólo sus restos originales, sino un siglo de intervenciones arqueológicas y arquitectónicas realizadas con criterios muy variados, claros exponentes del devenir y evolución de métodos y estrategias ${ }^{6}$.

Tras un análisis inicial de la situación de partida y la realización de los primeros trabajos de racionalización de la información, se decidió que la mejor forma de acometer el diagnóstico y las propuestas de conservación del ámbito de la nova urbs era la implementación de un sistema de información geográfica que, basado en la documentación gráfica existente y completada con los nuevos levantamientos, sirviera de contenedor de la nueva información generada. El SIG permitía la introducción, clasificación y consulta de datos relativos a la conservación e intervención de

\footnotetext{
${ }^{5}$ El equipo estaba formado por los arquitectos J.M. Guerrero, M. Castellano, F. Pastor, coordinado por F. Pinto. El trabajo fue realizado en el ámbito de un contrato LOU68/83 a través de la Universidad de Sevilla cuyo código de referencia es CGT:121/CP:413.

${ }^{6}$ Los resultados de estos trabajos están publicados en Pinto Puerto et al. (2010) y Pinto Puerto et al. (2011).
}

forma rápida y eficiente, así como la fácil cuantificación de los diversos campos de trabajo en un contexto de carácter territorial. Se trataba de una base de datos gráfica en la que los distintos elementos de estudio se constituían en entidades bidimensionales geo-referenciadas (punto, poli-línea o área), cuantificables de forma automática y contenedoras de información clasificada. Pero la principal carencia de esta herramienta radicaba precisamente en lo limitado de su condición bidimensional a la hora de afrontar objetos arquitectónicos o de infraestructura urbana dotados de características masivas o volumétricas y, en algunos casos, espaciales.

El modo de registrar la realidad ofrecida por el SIG no era sino una modernización del modo de interpretar los restos arqueológicos de Itálica en tiempos recientes. El apremio por la búsqueda de fiabilidad y rigor en las medidas hacía que dichos trabajos de interpretación se basaran fundamentalmente en lecturas de plantas de los edificios, donde es difícil comprender la complejidad espacial, los desniveles y adaptación a un terreno que es esencial conocer para comprender los restos. Antes de estas fechas se cuenta con numerosos dibujos de la ruina en perspectiva o aplicando las proyecciones ortogonales sistematizadas por Gaspar Monge a partir del siglo XVIII, pero éstas se ocupan de los edificios más significativos como las termas o el anfiteatro (dibujos de Elisha Kirkall de 1726, o los del Archivo Histórico Militar de autor anónimo ${ }^{7}$ ). Como excepción a esta costumbre están los dibujos que realizara en el s. XIX Demetrio de los Ríos, esforzándose en dibujar de una forma meticulosa y sistemática secciones de los diversos elementos donde quedaban expresados no sólo los atributos de figura y tamaño, sino los de textura y luz, consiguiendo una visualización bastante completa de los mismos. Con la entrada del nuevo siglo, y las nuevas excavaciones, los trabajos se racionalizan y también los dibujos que éstas generan, mucho más escuetos y asépticos. Las casas que fueron saliendo a la luz hasta configurar la nova urbs adrianea, gracias a los trabajos de Andrés Parladé entre 1919 y 1933, como consecuencia de las primeras campañas de excavaciones a gran escala, y los posteriores de Juan de Mata Carriazo y Francisco Collantes que recogen el estado de conservación de las ruinas, fueron documentadas a partir de numerosos dibujos donde domina la planta como elemento de interpretación del conjunto más fiable. Esta tendencia se consolidará en 1960 con los trabajos publicados de Antonio García y Bellido, donde aparecen los primeros casos de alzados y plantas no sólo de

Caballos, Marín y Rodríguez (1999) p.106. 
los restos conservados, sino de hipótesis de reconstrucción. Los trabajos posteriores realizados por José María Luzón entre 1970 y 1974 que afectaron a las casas del Planetario y las casas de la zona de la nova urbs denominada Cañada Honda, por la hondonada que se producía en el terreno, siguieron este mismo criterio. Sólo recientemente, y como consecuencia de la evolución de las nuevas tecnologías, se han ido produciendo visualizaciones en $3 \mathrm{~d}$, pero estas han estado más orientadas a la difusión y recreación virtual que a la investigación, careciendo, por lo tanto, del rigor necesario.

\section{OBJETIVOS}

Este trabajo se plantea como una extensión del encargo del Conjunto Arqueológico de Itálica, encaminada a desarrollar una experiencia piloto que intentara resolver las carencias detectadas en el SIG, que si bien solucionaba satisfactoriamente los requerimientos a nivel urbano, flaqueaba a la hora de enfrentarlo a la particularidad de cada resto arqueológico. Era necesario contar con un territorio común en el que se establecieran fluidas relaciones entre los diversos registros involucrados, que incluso pudieran visualizarse espacialmente, y cuyo objetivo último fuera obtener una representación sobre el propio edificio de toda la información generada por los procesos de investigación e intervención. Las características de muchos de los restos hacía necesario trascender las dos dimensiones del SIG hacia un sistema que permitiera alcanzar los siguientes objetivos:

- En un primer nivel, mejorar los recursos gráficos para la representación de los restos y la edición de planimetría mediante la generación de un modelo tridimensional. Aspecto éste del máximo interés en el ámbito de la difusión al encontrarnos actualmente dentro de un contexto temporal considerado por muchos intelectuales como la era de la cultura visual (Catalá 2005). Este modelo debería permitir la generación automática de proyecciones planas; no sólo plantas, sino también alzados y secciones cuyo aporte de información enriquecería enormemente la capacidad de análisis de los restos, máxime cuando tratamos casos muy condicionados por la topografía o constituidos por elementos emergentes precariamente conservados. A su vez, ofrecería la posibilidad de obtener vistas perspectivas como posibles herramientas de trabajo. Estas vistas y proyecciones se caracterizarían por el uso de líneas, grosores, etc., conforme a los criterios de normalización de la representación gráfica habituales en arquitectura (líneas de sección, líneas ocultas, caracterización de profundidades, etc.). Esto último implicaría la necesidad de que el modelo gráfico estuviera conformado por entidades dotadas de masa, susceptibles de ser seccionadas y capaces de ocultar a otras entidades. Por otro lado, este modelo debería surgir de una captura métrica rigurosa, que permitiera percibir cada una de las irregularidades existentes.

- En un segundo nivel, dotar a dichas entidades la capacidad de contener y generar información, es decir, hacer del modelo gráfico $3 \mathrm{~d}$ una maqueta virtual donde las formas no son meros gráficos vectoriales sino objetos con cualidades bien determinadas dentro de un entorno que permita su fácil visualización y edición. Sería un paso de aproximación de formas a unidades estratigráficas, elementos con cualidades constructivas, dotados de información sobre los procesos de conservación o intervención, etc. En el caso de estructuras de cierta regularidad formal podría tratarse de elementos parametrizables con gran capacidad de actualización.

- En un tercer nivel, vincular el modelo a una base de datos externa que se nutriera de los datos contenidos en él y aportara otros nuevos dentro del entorno de visualización utilizado, de forma semejante al desarrollo de un SIG, pero trascendiendo sus dos dimensiones a las tres que caracterizan cualquier arquitectura. De esta forma, este sistema de trabajo se constituiría como un nuevo modo de representación de la arquitectura patrimonial, y como consecuencia de sus restos arqueológicos.

El alcance de estos objetivos supondría el primer paso hacia un propósito más ambicioso: crear un sistema de información y gestión del patrimonio, que constituyera por sí mismo el levantamiento arquitectónico tal y como queda definido en la carta del Rilievo ${ }^{8}$. Este sistema de trabajo o herramienta facilitaría la relación de transversalidad entre los análisis que abordan el conocimiento del objeto desde las más diversas disciplinas y cuyos contenidos constituyeran la información básica e indispensable ante cualquier intervención sobre él. Tal y como se recoge en el artículo $2^{\circ}$ de la Carta de Venecia (ICOMOS, 1964) y sus posteriores actualizaciones, la captación de esa información debería desarrollarse previa, paralela y posteriormente al hecho de la conservación e intervención sobre un monumento, y a nuestro entender no sólo debería nutrirse del ámbito de la intervención, sino también de la investigación y la gestión del patrimonio. Esta herramienta utiliza-

\footnotetext{
${ }^{8}$ El documento de la Carta del Rilievo se divulgó con motivo del Seminario Internacional sobre "Gli strumenti di conoscenza peri 1 progetto di restauro» (Valmontone, septiembre de 1999) y el congreso internacional «Science et tecnologie pour la sauvagarde du patrimoine cultural Dans les pays du bassin Mediterranéen» (Paris 9 junio de 1999). En España se expuso en el VII Congreso de los departamentos de Expresión Gráfica Arquitectónica (Barcelona, mayo de 2000). Citado en Jiménez y Pinto (2003).
} 
ría el medio gráfico como base de su funcionamiento, y sería capaz de gestionar toda la información contenida y generada sobre un monumento, garantizando así el reconocimiento y puesta en valor documental de la mayor cantidad de sus valores patrimoniales.

En el caso concreto del Conjunto Arqueológico de Itálica, y de forma extrapolable a otros conjuntos monumentales o ámbitos territoriales, este sistema de información debería ser compatible con el SIG generado en los trabajos descritos anteriormente, de forma que su complementariedad pudiera abarcar todos los requerimientos demandados en los diversos ámbitos ya mencionados: investigación, conservación, intervención, gestión y difusión.

El trabajo descrito en este artículo, dada su condición de punto de partida de un proceso investigador más amplio, se enfocó hacia la consecución de los objetivos antes marcados siguiendo un proceso de trabajo bien acotado:

- Análisis de los distintos sistemas de captura como instrumentos para la obtención de un modelo alámbrico riguroso formal y métricamente del objeto arquitectónico, como base de la posterior construcción de un modelo tridimensional de entidades masivas.

- Evaluación del uso de un modelo de entidades masivas frente a otros tipos de entidades gráficas como base para un sistema de información y gestión, e indagar sobre las posibles técnicas de modelado capaces de generarlo.

- Estudio de los mecanismos y herramientas que permiten conectar la representación gráfica de ese modelo masivo con una base de datos que contenga toda la información complementaria del objeto arquitectónico.

- Aplicar los procesos anteriores en el diseño de una base gráfica interrelacionada con una síntesis de datos externos a partir de un objeto arquitectónico concreto: Casa de Hylas del Conjunto Arqueológico de Itálica.

\section{CASA DE HYLAS}

El actual Conjunto Arqueológico de Itálica está formado por un heterogéneo grupo de propiedades. Algunas se encuentran dispersas en forma de solares dentro de la población de Santiponce - que ocupa actualmente el recinto de la antigua ciudad romana-, otras son reconocibles como unidades monumentales aisladas en los márgenes de esta ciudad como el Teatro, o en medio del campo como las cisternas, y otras conforman una única y enorme propiedad vallada que contiene a la Nova Urbs o ampliación urbana de la antigua ciudad, junto con el anfiteatro. La Nova Urbs, por extensión e importancia, es la estructura urbana de mayor envergadura del conjunto, y surge a partir del siglo II ${ }^{9}$ como una planificación urbana uniforme siguiendo un esquema de tipo hipodámico cuya retícula se adapta a la topografía sin alterar su potente geometría en planta.

La elección de los restos arqueológicos de una casa de la nova urbs como modelo de experimentación respondió a varias circunstancias. Por un lado, como se ha mencionado en los antecedentes, este trabajo surge como extensión de un encargo que abarcaba, entre otros fines, la realización de una serie de levantamientos que completaran la documentación gráfica existente sobre el conjunto arqueológico. Era por tanto preceptivo que la elección estuviera entre los restos que carecían de levantamiento.

Por otro lado, las características de los inmuebles que forman parte del conjunto, todos restos arqueológicos de arquitectura doméstica y pública romanas (s. I y II d.C), permitían experimentar y valorar la aplicación de este método de trabajo en un objeto arquitectónico de cierta complejidad formal, pero de un tamaño razonable. La variedad en los estados de conservación de estructuras excavadas a lo largo de la primera mitad del siglo pasado permitían afrontar el modelado de elementos de características morfológicas y dimensionales muy dispares, ubicados a su vez en un contexto físico transformado tanto por las intervenciones arqueológicas como por los diversos agentes naturales y los procesos de expolio sistemático.

Finalmente, la decisión se concretó por el problema más acuciante, a nuestro juicio, del Conjunto arqueológico, y que procede de la estratigrafía geotécnica y la topografía del terreno donde se cimientan las distintas edificaciones. Es fácilmente apreciable una zona de arrastres y depósitos que históricamente ha provocado derrumbes y movimientos de tierras, desfigurando los niveles de las casas allí asentadas. Entre ellas está la casa de Hylas, cuya ubicación ha dado lugar a una parcela de topografía aterrazada (Fig. 2) donde prevalece la pérdida de material debida a las escorrentías, y cuyos restos están marcados por desplomes, desgastes y vuelcos que han dado lugar a un grado de degradación especialmente grave. Las condiciones topográficas afectaban de forma especial a la estructura constructiva y espacial de este inmueble, dando como resultado una de las estructuras domésticas más interesantes y amplias de esta nueva ciudad —así lo recogía ya García y Bellido ${ }^{10}$ en su breve descripción de la casa- ya que se encuentra entre los ejemplos cuya organización

\footnotetext{
${ }^{9}$ García y Bellido (1985).

${ }^{10}$ García y Bellido (1985), p. 97-98.
} 
interna y posible orientación diferente al resto de las casas conocidas $^{11}$-norte/sur.

La Casa de Hylas se denomina así por el mosaico que alberga una de las estancias, que representa el rapto de Hylas por las Ninfas, presidido por Hércules. Esta denominación fue sustituida en la base gráfica elaborada para el conjunto, por un identificador que indicaba su ubicación respecto a la estructura urbana, seguido del apodo por el que se la conoce en la actualidad -CAI_A_1_2HYLAS-.

La historia arqueológica de esta casa es relativamente reciente y se remonta a los años setenta del pasado siglo, cuando se profundiza en la detección de la estructura urbana más al norte de la nova urbs por José María Luzón. Hasta entonces sólo se conocía la geometría de la cuadrícula que formaba las manzanas o insulae, ocupadas en esta parte noreste de recinto urbano, por dos casas adosadas por sus lados cortos mediante un muro doble. Las primeras prospecciones realizadas por el Conde de Aguiar descubrieron esta zona, centrándose en la búsqueda de mosaicos como los de la casa de los Pájaros, vecina a la de Hylas. Debemos esperar, por tanto, a las campañas llevadas a cabo en 1970 para conocer las características constructivas de las calles, fuentes, cruces y galerías porticadas que formaban el espacio urbano. En estas fechas se descubre la casa de Cañada Honda, al sur de la de Hylas, completando con ésta y la de los Pájaros una de las zonas más significativas del parcelario adrianeo.

El inmueble se encuentra parcialmente excavado, pues parte de su estructura y su adosamiento a la casa medianera está bajo el actual cementerio de Santiponce. Es, por tanto, una estructura incompleta, de la que se desconoce la parte más profunda de la casa, la más privada y alejada del acceso, situado al norte. A pesar de no estar completamente excavada se han planteado algunos aspectos característicos. J.M. Luzón observó como la casa se adaptó al terreno, a diferencia de la Casa de Cañada Honda, levantada sobre una explanación. Esto hace que las dependencias de la casa se sitúen a diversos niveles salvados por peldaños ubicados en los límites de las galerías. Por otro lado, su estructura no sigue una simetría tan rigurosa como la Casa de los Pájaros, organizándose sus dependencias de forma más irregular a causa de la accidentada topografía.

Esta topografía es uno de los elementos más determinantes en la conservación del edificio, pues los arrastres debidos a aguas de lluvias son frecuentes, provocando la constante erosión de unos restos ya por si muy mermados

\footnotetext{
${ }^{11}$ Caballos, Marín y Rodríguez (1999), p.82, y Mañas Romero (2010), p. 84-85.
}

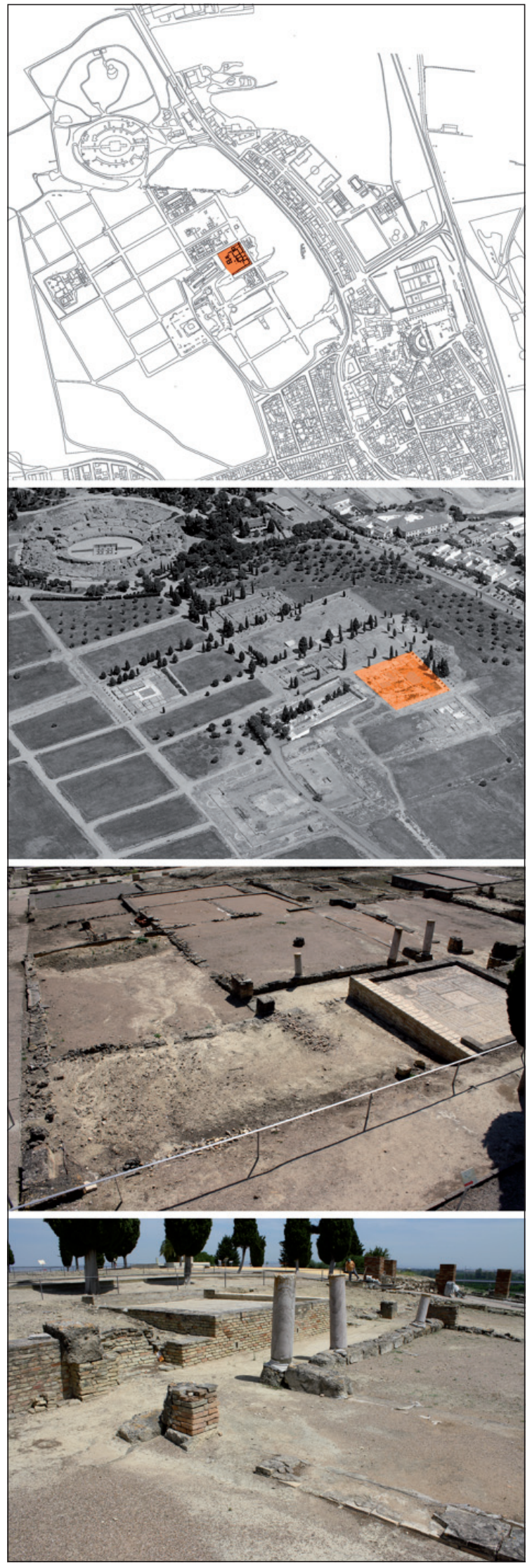

Fig. 2. Situación de la casa de Hylas dentro del Conjunto Arqueológico de Itálica (Santiponce. Sevilla) 
por los sucesivos expolios sufridos en el siglo XIX, tras quedar a la luz la estructura urbana por las caóticas excavaciones llevadas a cabo durante ese siglo. El intento por racionalizar la ruina, mejorar su conocimiento y planificar su protección emprendida en 1933, quedó interrumpida por la guerra civil, retomándose sólo en 1956, recuperando los trabajos de deslindes y ordenación del recinto ${ }^{12}$. Mientras tanto, la época de penuria económica de la guerra y la Postguerra propició la búsqueda masiva de materiales de construcción que aprovechaban las brechas abiertas por las primeras excavaciones. Posteriormente se realizaron labores de recrecimiento de algunos elementos portantes y muros perimetrales hacia 1960, con el objetivo de hacer comprender la ruina a los visitantes, así como nuevas excavaciones a cargo de Ramón Corzo en $1975^{13}$.

Estas circunstancias, unidas a la sobre-excavación de muchas de las estancias por la insistente búsqueda de mosaicos o las nivelaciones rehechas para mantener los estratos descubiertos, han propiciado la situación actual de la casa. Su forma está definida por estructuras murales poco emergentes que limitan plataformas escalonadas en consonancia con la pendiente de la parcela, describiendo una trama ortogonal pero carente de simetría y donde destacan algunos soportes conservados sólo de forma parcial.

\section{LEVANTAMIENTO GRÁFICO}

Los levantamientos realizados hasta la fecha en el conjunto arqueológico habían abordado con rigor la captura métrica general, pero desde un enfoque topográfico, respondiendo a una necesidad de control de la superficie del terreno y tratando los restos arqueológicos como simples accidentes de éste. Por esta razón, en los nuevos levantamientos se procuró mejorar la atención a lo arquitectónico, lo cual requería de una reflexión previa sobre lo que se pretendía capturar y registrar gráficamente, que no era otra cosa que la propia ruina. Además, en el caso concreto de la Casa de Hylas, la escasez de información - debido en parte a que se encuentra excavada sólo parcialmente- obligaría a que el levantamiento quedase abierto, situación ésta muy valiosa a la hora de experimentar un sistema de trabajo cuya potencialidad principal radicaría precisamente en su capacidad de actualización. Además, lo accidentado de su topografía requería de herramientas gráficas más potentes que permitieran una interpretación más rigurosa.

\footnotetext{
${ }^{12}$ Mata Carriazo (1963).

${ }^{13}$ Corzo Sánchez (1982)
}

En ese sentido, contamos en la actualidad con sistemas de captura métrica y desarrollo gráfico digital que combina la fotografía y el software de generación y gestión de dibujos. La fotogrametría ha evolucionado con la informática agilizando los costosos procesos de trabajo de campo, y facilitando incluso la modificación de los resultados mediante sucesivas entradas de nuevos datos fotográficos y métricos. Por otro lado, este campo ha experimentado interesantes avances gracias a la reciente aparición de implementaciones de software de fotogrametría y nuevos sistemas derivados de la topografía para la captación de datos morfológicos y dimensionales ${ }^{14}$, permitiendo registrar incluso la textura y el cromatismo de los objetos documentados. Dentro de este ámbito de trabajo existen interesantes aportaciones en la aplicación a los procesos de documentación y análisis del patrimonio ${ }^{15}$.

Esta etapa del proceso suponía el punto de partida de la elaboración de este sistema experimental. Su desarrollo se fundamentó en la elaboración, por medio de un sistema de levantamiento indirecto, de una representación formalmente rigurosa y métricamente precisa del objeto arquitectónico a partir de una serie de datos captados in situ. En general, la captación de la realidad física del objeto arquitectónico y su traducción a un soporte gráfico llevan implícita una discriminación de datos. Es del todo imposible, y a su vez innecesario, intentar extraer y representar toda la complejidad que lo caracteriza, siendo ineludible desarrollar un proceso de reflexión paralelo que guíe esta etapa hacia un objetivo concreto, en este caso el posterior modelado tridimensional de los restos. Esta reflexión adquiría más importancia si cabe debido a la heterogeneidad formal que caracterizaban las estructuras visibles de la casa, constituidas tanto por elementos dotados de cierta regularidad gracias a intervenciones recientes, como por otros de extrema irregularidad debido a los efectos devastadores del paso del tiempo. Estas consideraciones nos llevaron a optar por la fotogrametría como método de levantamiento. De esta forma, los datos captados in situ consistieron, por un lado en una serie de fotografías de características determinadas que servirán de base para la restitución formal del objeto, y por otro mediciones topográficas de puntos de apoyo que proporcionaron la

\footnotetext{
${ }^{14}$ Navarro y Cabanes (2009). Navarro et al. (2011). Lerma et al. (2011). Mesa et al. (2009). San José (2011).

${ }^{15}$ Mañana-Borrazas et al. (2008). Y también el Proyecto OPTOCANTIERI. Instituto de Física Aplicada "Nello Carrara» (Florencia). Dedicado al desarrollo de herramientas informáticas para la captura dimensional, con escáner 3D. Web: http://optocantieri.ifac.cnr.it/. Grupo LFA-DAVAP (Laboratorio de fotogrametría arquitectónica - Documentación, análisis y visualización avanzada del patrimonio). Web: http://157.88.193.21/-lfa-davap/index.php.
} 
escala y la ubicación referenciada a un sistema de coordenadas general.

La fotogrametría supera considerablemente en precisión y reducción de tiempos a sistemas directos tradicionales, $y$, por otro lado, en capacidad de discriminación de información y en economía de medios a sistemas tecnológicamente más avanzados como el escáner láser. Este último sistema aventaja a la fotogrametría en rapidez, precisión y automatismo, pero hasta hace relativamente poco tiempo adolecía precisamente de la capacidad de incluir ese proceso reflexivo capaz de discriminar o clasificar la ingente cantidad de información que son capaces de aportar. La aparición en los últimos tiempos de aplicaciones informáticas capaces de gestionar con solvencia las nubes de puntos generadas por el escáner ha potenciado enormemente el rendimiento de esta herramienta en la obtención de levantamientos útiles en el ámbito de la arquitectura y la arqueología. En nuestro caso, la escasez de medios económicos nos hizo desechar la opción del escáner en favor de la fotogrametría, enfocando la restitución hacia la obtención de un modelo alámbrico del objeto destinado al posterior modelado de entidades masivas, adaptándose correctamente a medios y tiempo disponibles.

También se recurrió a sistemas topográficos como apoyo a la fotogrametría, así como para la toma de datos de estructuras de poca complejidad — principalmente elementos de infraestructura y urbanización-, verificación de niveles de solería en interior del inmueble y captura de otros elementos puntuales.

La falta de homogeneidad de muchos de los restos y el avanzado estado de disgregación sufrido por algunas estructuras obligaron a simplificar la restitución en algunas zonas, pero siempre en base a criterios de fácil interpretación. Se recurrió a la sustitución mediante volúmenes capaces en aquellos casos en los que el deterioro de los elementos murales o pilastras hacía imposible una correcta definición de aristas o contornos. En el caso de las estructuras totalmente disgregadas o simplemente marcadas en procesos arqueológicos, la sustitución consistió en la delimitación de superficies proyectadas en el terreno. La superficie de terreno no excavada fue restituida mediante puntos aislados, líneas de rotura y líneas de conexión con estructuras emergentes. En general, esta restitución dio lugar a una abstracción reflexionada del objeto arquitectónico que facilitara su posterior modelado con elementos masivos, y que contuviera la información morfológica y dimensional suficiente para permitir posteriores procesos de catalogación, medición y valoración.

\section{GENERACIÓN DEL MODELO TRIDIMENSIONAL}

Sigue siendo un campo poco explorado la conversión de los datos generados en un levantamiento en entidades gráficas tridimensionales susceptibles de aportar información sobre su geometría y sus características físicas. En este sentido existen aplicaciones informáticas que transforman nubes de puntos — generadas mediante escaneado láser o mediante procesos fotogramétricos - en superficies que reproducen con gran fidelidad los paramentos capturados. Éstas son entidades huecas, sin información sobre su masividad, y de difícil edición y segregación en elementos constructivos unitarios, pero muy útiles en el caso de elementos carentes de una geometría definida. En esa línea existen algunas aportaciones, como los trabajos realizados por miembros de la Universidad Politécnica de Cataluña ${ }^{16}$, experiencias en la generación de modelos digitales tridimensionales enfocadas a su uso como instrumento para el análisis perceptivo de la arquitectura o la comprensión visual del monumento ${ }^{17}$, o la reciente aparición de software de generación de entidades BIM a partir de nube de puntos. Podemos mencionar también recientes congresos sobre lo que se ha venido a denominar arqueología virtual ${ }^{18}$ que han mostrado los campos de actuación prioritarios actualmente en este nuevo ámbito de la arqueología, y dirigidos fundamentalmente a la reconstrucción virtual del Patrimonio Arqueológico con vistas a su investigación y difusión en museos o plataformas web. En cualquier caso este trabajo se aparta de líneas de investigación dedicadas meramente al ámbito de la difusión, o lo que ha venido a llamarse realidad virtual, lo cual no impide que se tenga presente los avances en este terreno, pues se ponen en práctica multitud de herramientas de simulación.

La modelización de elementos masivos a partir de la estructura alámbrica obtenida por fotogrametría responde a la finalidad de generar entidades gráficas capaces de ofrecer una serie de utilidades adicionales frente a otras entidades de tipo bidimensional o superficial: son capaces de contener y proporcionar características dimensionales y propiedades físicas y materiales, facilitando operaciones de clasificación, medición, valoración y análisis estructurales; son susceptibles de editar fácilmente con objeto de actualizar su morfología y dimensionamiento respecto a las posibles actuaciones de que pueda ser objeto la arquitectu-

\footnotetext{
${ }^{16}$ Mesa (2006)

${ }^{17}$ Almagro Vidal (2008). Vale y Rodríguez (2011). Goitia (2010).

${ }^{18}$ I y II Congreso internacional de Arqueología e informática gráfica. Patrimonio e innovación, Arqueología 2.0. Ediciones 2009 y 2010. Organizados por el grupo de investigación de la Universidad de Sevilla VIRTUS. // www. arqueologiavirtual.com.
} 


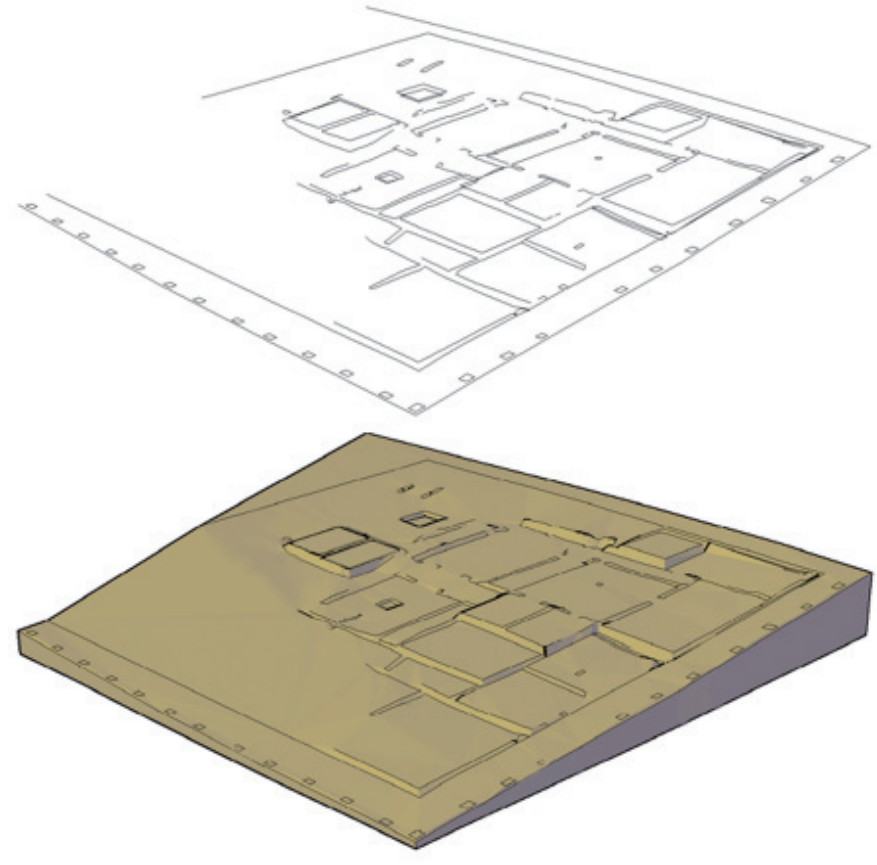

Fig. 3. Generación masiva del terrero a partir de fotogrametría

ra que sustituye; y su condición de volúmenes masivos les proporciona la facultad de poder ocultar las aristas y líneas de contorno no visibles facilitando así la obtención de planos convencionales de planta, alzado o sección.

Estos atributos, unidos a la operatividad de un entorno de trabajo BIM, dotarían a la base gráfica de una serie de beneficios adicionales frente a otros sistemas basados en objetos alámbricos obtenidos directamente de la fotogrametría, permitiendo alcanzar los objetivos marcados.

En cuanto al software, para la realización del modelo se optó por la opción que ofrecía Autocad Architecture ${ }^{19}$ (ACD-A a partir de ahora). Este software, además de ofrecer la ventaja de estar basado en una plataforma muy extendida, está concebido bajo un entorno $\mathrm{BIM}^{20}$, lo cual permite generar directamente elementos arquitectónicos basados en entidades paramétricas, siempre que los elementos modelados tengan cierta regularidad formal, o a partir de la conversión de sólidos o mallas policaras cerradas en el caso de elementos muy irregulares.

Así, el terreno se modeló automáticamente a partir de puntos aislados, líneas de rotura y líneas de intersección

\footnotetext{
${ }^{19}$ www.autodesk.es

${ }^{20}$ Building Information Modeling o modelado de información de construcción o del edificio. Se trata de un tipo de software evolucionado del CAD, de gran proyección actualmente en lo referente a la arquitectura de nueva planta y con escasa repercusión en el ámbito del patrimonio. La principal baza de esta tecnología es la sustitución de la representación vectorial en que se basa el CAD tradicional por la representación basada en elementos constructivos de tipo paramétrico.
}

entre el terreno y los elementos emergentes (Fig. 3), generando un elemento masivo, apoyado en el plano XY, que constituyó el referente espacial. El resto de elementos constructivos se vincularon al terreno de forma que cualquier variación modificaría la posición y morfología de la superficie de intersección. De esta forma, la actualización de la topografía a posibles intervenciones arqueológicas modificaría automáticamente las características volumétricas de los elementos constructivos en contacto con el terreno.

En general los restos conservados se sustituyeron directamente por elementos arquitectónicos a partir de la introducción de los datos paramétricos necesarios según el tipo de geometría asociada (Fig. 4). De esta forma se modelaron los siguientes tipos de elementos: elementos murales bien conservados, pilastras prismáticas, fustes de columnas, solerías, y otros elementos auxiliares como los elementos de protección de las ruinas.

Los restos que respondían a geometrías muy irregulares se modelaron mediante la generación de mallas policaras cerradas a partir de los contornos obtenidos en la fotogrametría (Fig. 5). Posteriormente estas entidades superficiales (no masivas) se convirtieron en elementos de masa susceptibles de proporcionar información relativa a su masividad y recibir otros tipos de atributos. En este grupo se encuentran los elementos murales degradados, basas de columnas, elementos de solería disgregados o escalonados, elementos de infraestructura (canales, cloacas, etc.) y otros restos no identificados y carentes de regularidad formal.

Todas las entidades creadas, además de clasificarlas en capas en función del tipo de objeto arquitectónico (para facilitar su edición), se marcaron con una identificación alfanumérica que hacía referencia al tipo de objeto arquitectónico y se le asociaron propiedades físicas (tipo de fábrica y material) y otras relativas a su estado de conservación: tipo de patología y su gravedad, tipo de intervención, etc., todos ellos datos basados en las fichas diagnóstico realizadas durante los trabajos encargados por el conjunto arqueológico. Estos atributos podían ser visualizados en forma de gráficos tematizados y modificados individualmente o en grupo, facilitando así la actualización en tiempo real de posibles modificaciones del estado de conservación de los restos, así como el registro de nuevas actuaciones.

Llegados a este punto es importante recalcar que el modo en que se genere la imagen del modelo es un tema que debe abordarse también con cuidado, pues los códigos y convenios gráficos o infográficos aplicados pueden deri- 

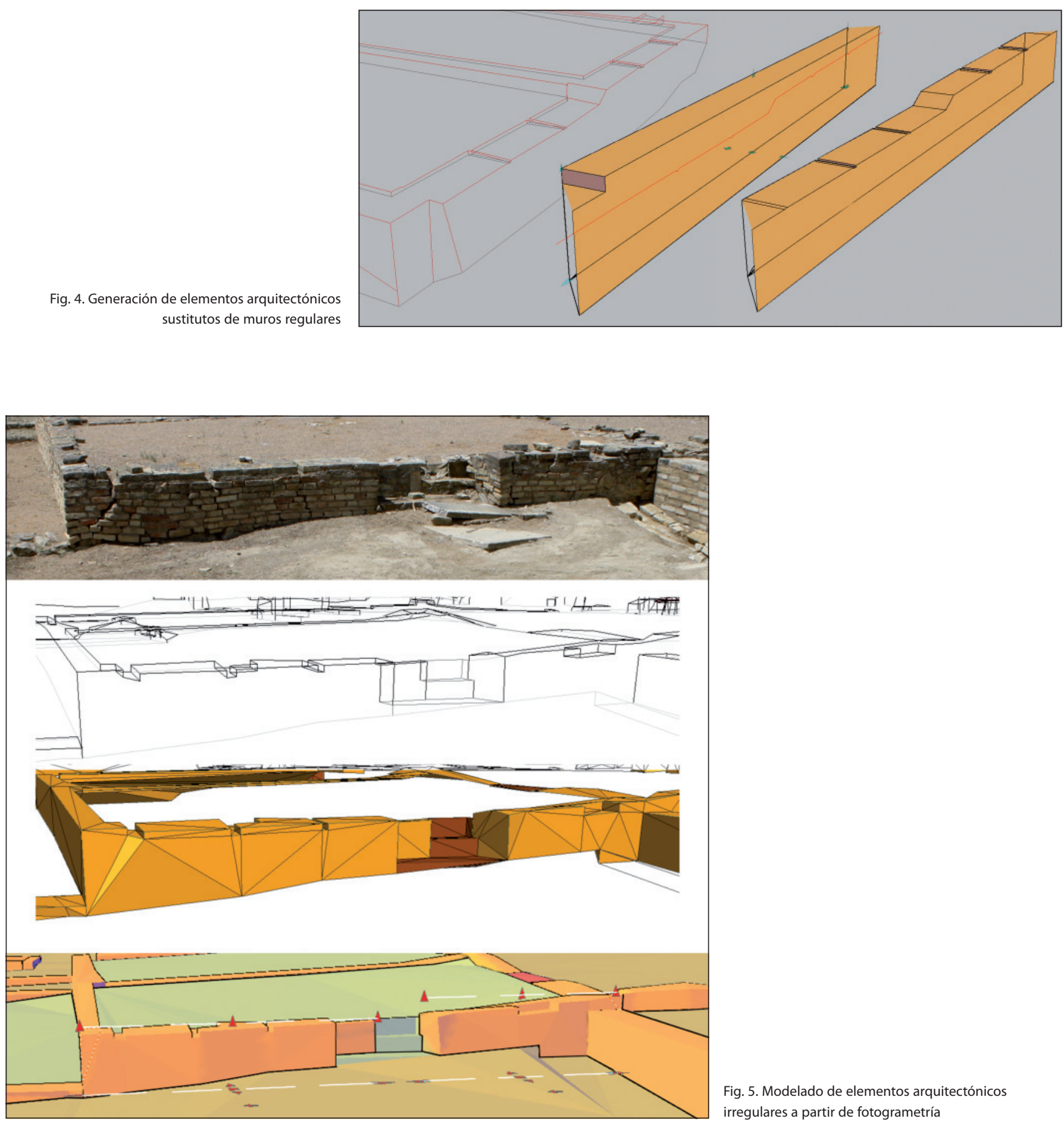

Fig. 5. Modelado de elementos arquitectónicos irregulares a partir de fotogrametría

var en una realidad virtual recreativa no pretendida en este trabajo. La adopción de unos criterios claros y condicionantes del resultado primó sobre una intención de verosimilitud con la realidad, aportando la abstracción suficiente para evitar la sustitución del objeto por su imagen (Fig. 6). Esta codificación pretendidamente abstracta en el tratamiento del objeto ayuda a comprender el modelo como un instrumento de conocimiento, no de entretenimiento, facilitando su uso y adaptación a condiciones que pueden llegar a ser sumamente complejas. El objetivo último de esta experiencia era la de crear una herramienta que facilite la profundización en el conocimiento y comprensión de la arquitectura y esté al servicio de futuros mecanismos de conservación e intervención. 


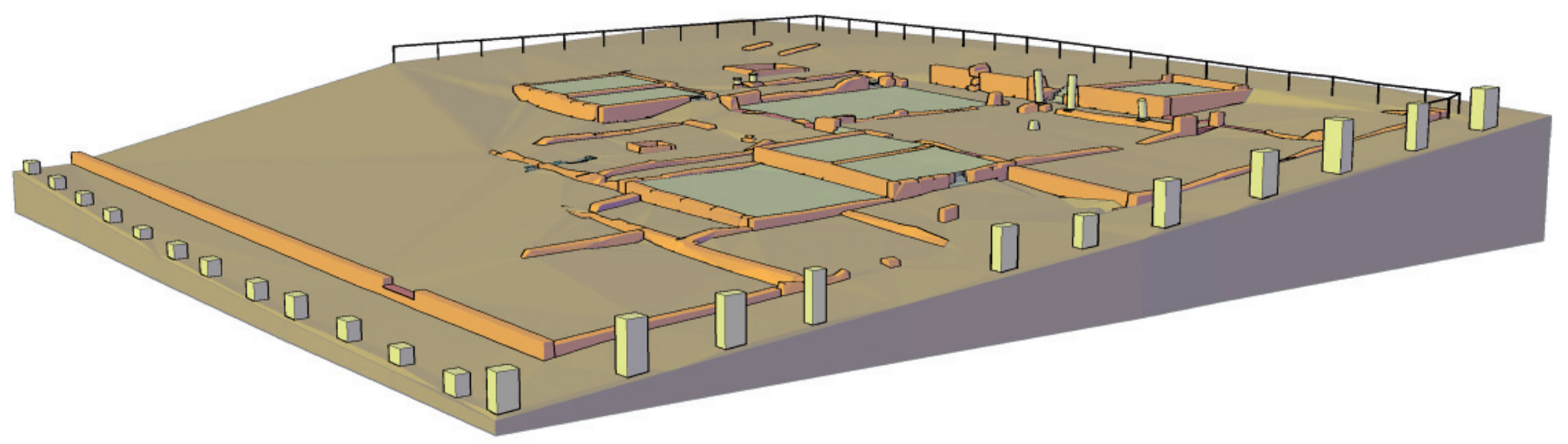

Fig. 6. Modelo infográfico completo de la Casa de Hylas

Por otro lado, el hecho de haber realizado el levantamiento mediante fotogrametría ofrecía una ventaja adicional: la posibilidad de revertir el proceso para la obtención de información sobre la apariencia y naturaleza de los restos. Las aplicaciones de fotogrametría modernas ofrecen la posibilidad de importar información gráfica en forma de mallas trianguladas y aplicarles de forma precisa las texturas obtenidas de tomas fotográficas previamente orientadas (Fig. 7). Este proceso, de fácil implementación, posibilitaría la generación de nuevos documentos gráficos de objetos individuales o de conjunto, en formatos muy extendidos - como PDF 3D—, que vinculados de forma externa a las entidades de nuestro modelo facilitaran el análisis de los restos, aportando información adicional a la planimetría o pudiendo formar parte de la estructura de un inventario.

\section{INTERRELACIÓN DE INFORMACIÓN CLASIFICADA. BASE DE DATOS EXTERNA}

Podemos definir la interrelación de datos como la conexión de la base gráfica con las importantes bolsas de datos contenedoras de notas históricas, culturales, constructivas, estructurales y patológicas procedentes tanto de una aproximación documental previa y meditada sobre el objeto

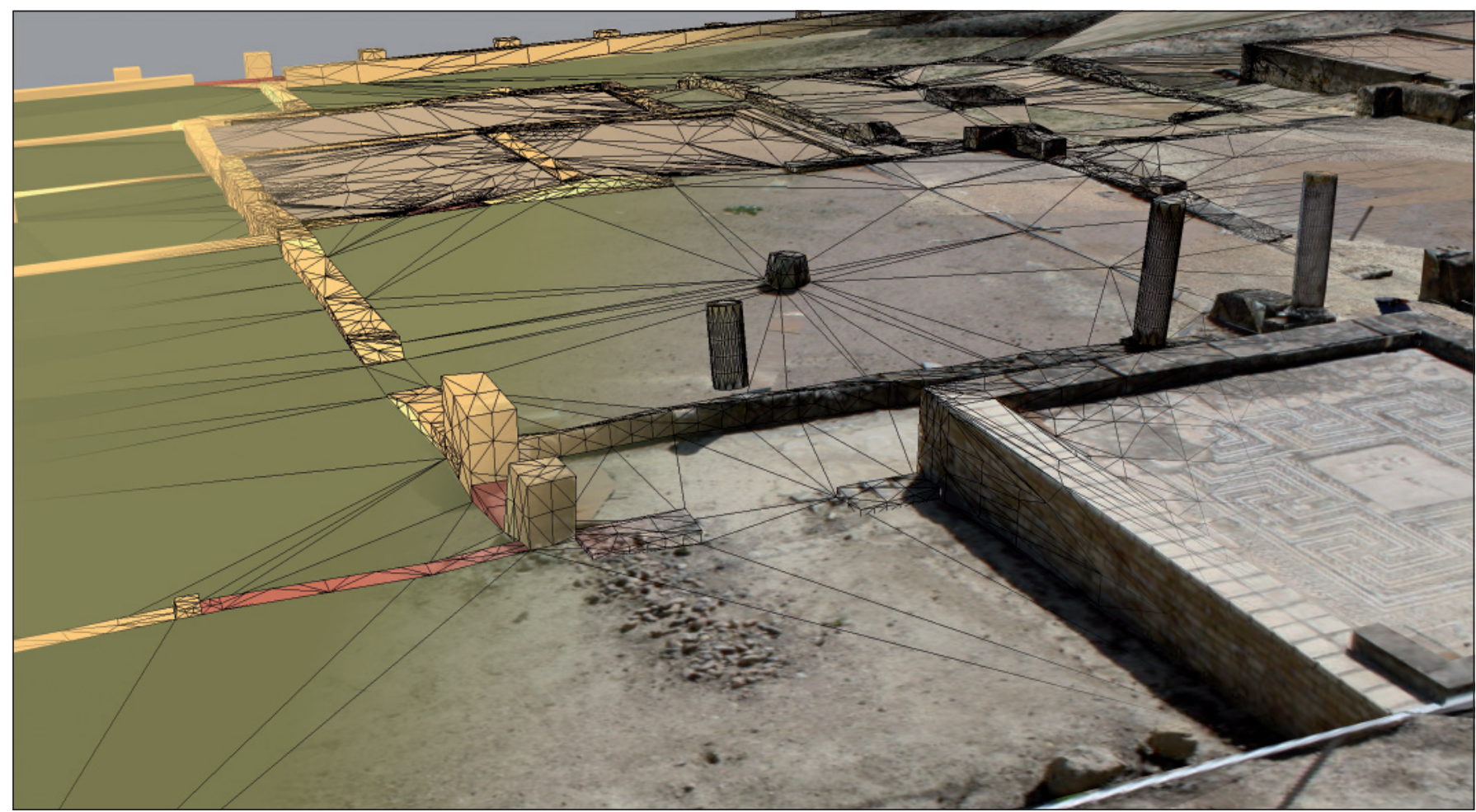


Fig. 8. Vinculación de modelo a base de datos en entorno ACD-A

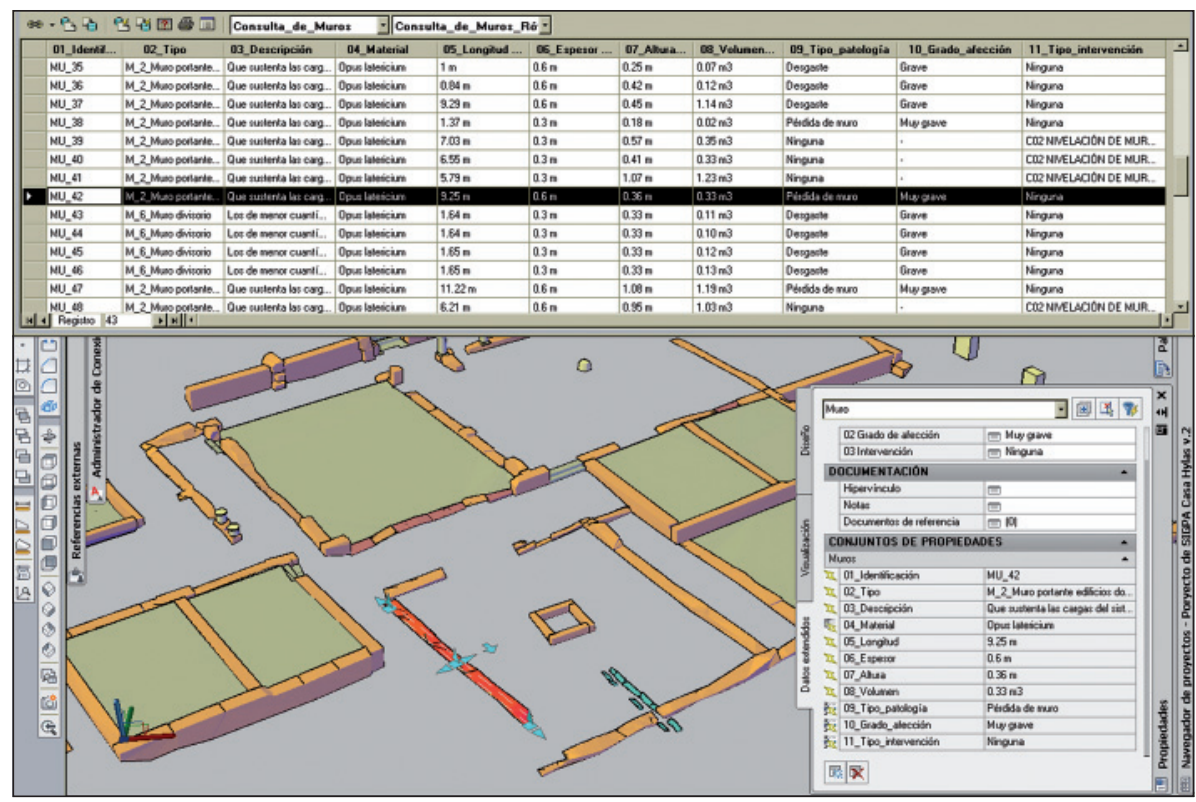

(comprensión crítica previa), como de observaciones y ensayos nuevos y originales, fruto de la frecuentación directa del monumento. En este ámbito contamos en la actualidad con sistemas informáticos de ordenación y gestión de una información cada vez más ingente consistentes en bases de datos aplicables a una importante gama de requerimientos. Sin embargo, estas experiencias se siguen desarrollando en el marco de disciplinas aisladas o escasamente relacionadas, que sólo en algunos casos son superadas por verdaderas propuestas de interrelación de datos. En esta dirección apuntan aún pocos trabajos, destacan experiencias basadas en sistemas GIS como las de la Universidad de Valladolid ${ }^{21}$ o el realizado por Leandro Cámara y Pablo Latorre ${ }^{22}$ para el Plan Director de la Catedral de Vitoria, que supuso un importante avance en esta materia.

En ese sentido, este trabajo se culminó con la indagación sobre los posibles mecanismos de conexión entre las entidades gráficas que constituían el modelo, junto con sus atributos, y la información de tipo alfanumérica incluida en una base de datos externa y procedente de notas históricas, culturales, constructivas, estructurales y patológicas. Esta etapa final no pretendió ser la culminación o finalización de un proceso, sino un punto y seguido dentro de una línea de investigación que sigue avanzando. Es por tanto una etapa inacabada que ofreció la oportunidad de experimentar una serie de mecanismos que pueden llegar a ser de gran utilidad dentro de un sistema general de

\footnotetext{
${ }^{21}$ Fernández (2007) y Fernández y San José (2000).

${ }^{22}$ AA. VV. (1999).
}

información y gestión del patrimonio. Esta experimentación se centró en un software concreto, el mismo utilizado para la etapa anterior, con objeto de buscar una plataforma gráfica que pudiera sostener casi todo el proceso.

ACD-A permite configurar una base de datos externa utilizando los programas ODBC ${ }^{23}$ y OLE DB de Microsoft, gracias a los cuales la aplicación puede utilizar datos procedentes de otras aplicaciones, con independencia del formato en el que se hayan almacenado o la plataforma de base de datos en la que se hayan creado. La conexión se crea a partir de un origen de datos que puede ser tanto una tabla como un conjunto de tablas almacenadas en un entorno, catálogo o esquema ${ }^{24}$. En concreto esta función de conectividad admite las siguientes aplicaciones externas: Microsoft Access, dBASE, Microsoft Excel, Oracle, Paradox, Microsoft Visual FoxPro y Servidor SQL.

En este caso se buscaba construir un vínculo con una base de datos externa que permitiera establecer un trasvase de información en dos direcciones. Por un lado la base de datos externa debía nutrirse de los atributos contenidos en los objetos arquitectónicos que conformaban el modelo, de forma que cualquier modificación en dichos datos la actualizara automáticamente. Por otro lado, la adición o manipulación de información de la base de datos debía poder reflejarse en el entorno gráfico.

La base de datos se creó mediante la vinculación de tablas exportadas desde ACD-A que contienen todos los

\footnotetext{
${ }^{23}$ Open Database Connectivity: Conectividad abierta de bases de datos.

${ }^{24}$ Sistema jerárquico de clasificación de información comúnmente utilizado por cualquier programa de gestión de base de datos.
} 


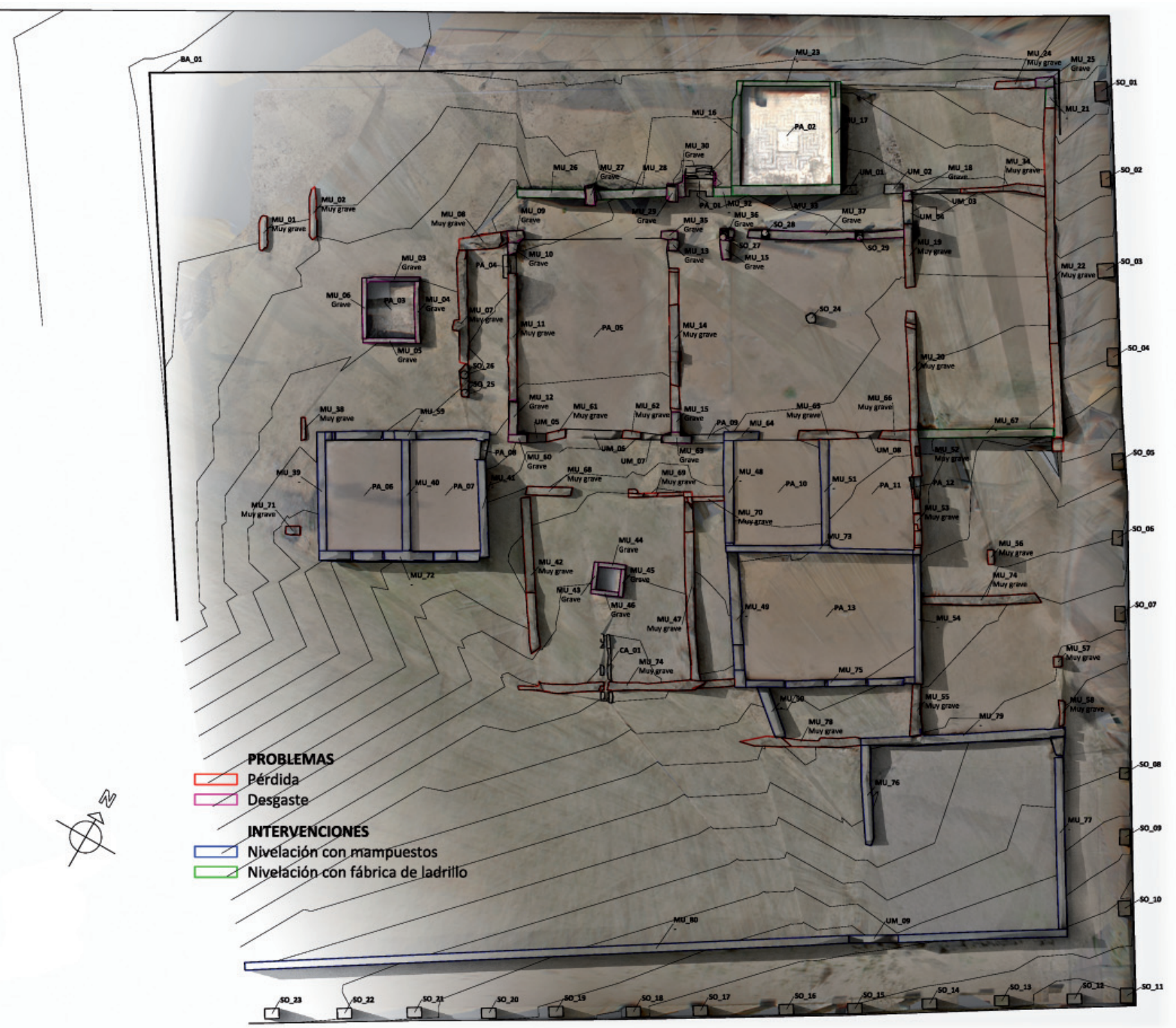

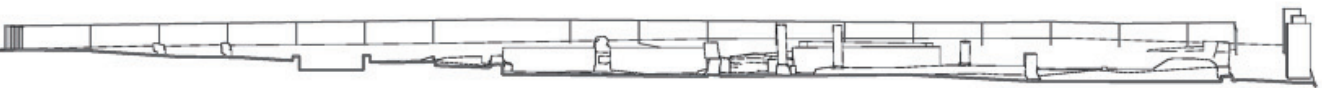
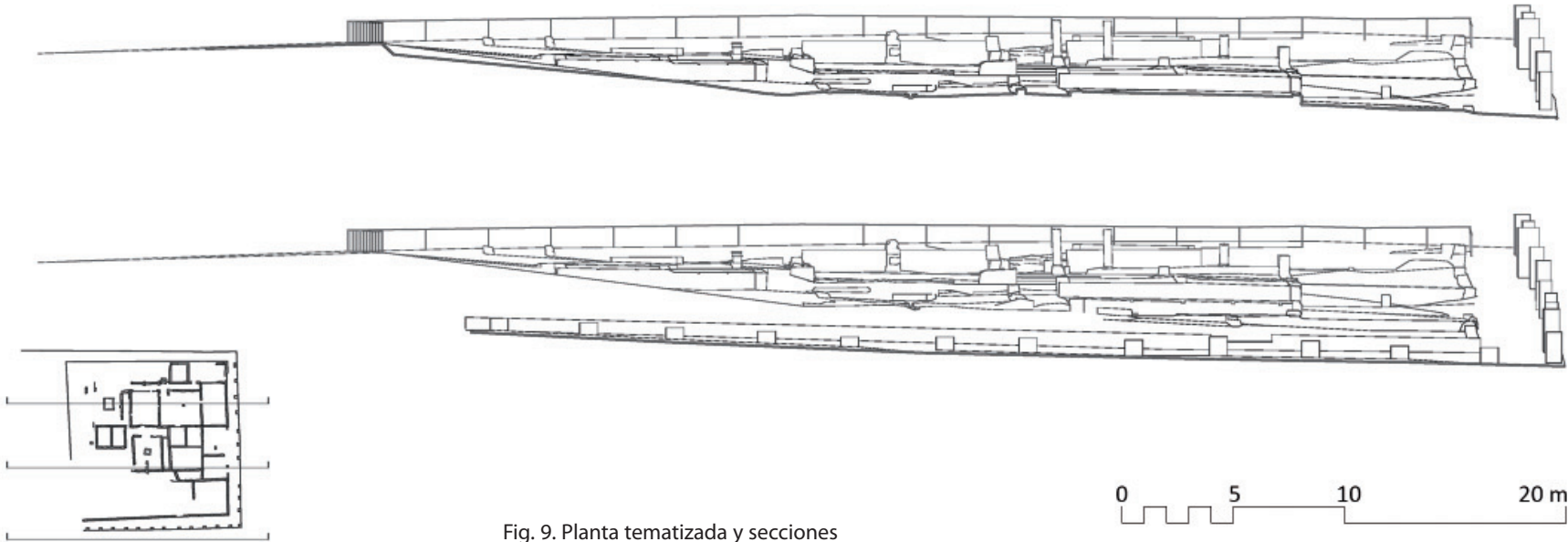

Fig. 9. Planta tematizada y secciones

$\stackrel{0}{5} 10 \quad 20 \mathrm{~m}$


datos de propiedades del modelo del edificio, de forma que cada registro se corresponde con una entidad gráfica concreta. Una vez creada la base de datos externa se estableció su conexión con el dibujo y la vinculación individual de cada registro con su objeto. Esta vinculación permite la generación de consultas en ambas direcciones, de forma que se pueden realizar búsquedas de registros en la base de datos a partir de la selección de entidades gráficas y a la inversa, con lo cual la interrelación de información queda garantizada (Fig. 8). La selección, tanto de registros en la base de datos como de objetos gráficos puede realizarse mediante la acotación de los valores de sus atributos. También pueden vincularse a los objetos gráficos otros datos externos como imágenes o documentos de consulta mediante hipervínculos.

La utilidad de esta interrelación de datos radica en la posibilidad de clasificar y documentar cualquier tipo de información, ya sea ésta gráfica o alfanumérica, a partir de un entorno gráfico que sirve de guía en todo el proceso. Éste entorno gráfico no sólo hace las funciones de índice de contenidos sino que, a su vez, constituye por sí mismo parte de la información, de forma que su vinculación con el resto de datos posibilita la actualización en tiempo real de toda la información contenida. A partir de esta herramienta podemos generar información gráfica en forma de planos (Fig. 9), o crear informes, mediciones o valoraciones mediante la manipulación en MS Access de la base de datos externa o incluso la exportación de sus datos a otras aplicaciones. Ambos tipos de documentos — gráficos y alfanuméricos - tienen la especial cualidad de ser el volcado directo de una base de datos de soporte gráfico cuya modificación los actualiza de forma automática.

\section{CONCLUSIONES}

En primer lugar, la fotogrametría ha servido para capturar los datos morfológicos y dimensionales necesarios para su utilización en un proceso posterior: la modelización masiva del edificio. Fue por tanto, esencial realizar un análisis previo de los posibles sistemas de modelado y sus requerimientos. Así, la novedad del levantamiento realizado radica en un cambio de objetivo: no ha consistido en realizar un «calco» de la realidad física de los restos en proyecciones ortogonales concretas que den lugar a alzados o secciones (verticales u horizontales), finalidad habitual de este tipo de trabajos, sino en un análisis de su morfología encaminado a sintetizar sus líneas generadoras. De esta forma, la planimetría convencional obtenida no se supedita a decisiones iniciales condicionadas por unas circunstancias o finalidades concretas (documentación general del edificio, investigaciones temáticas, intervenciones parciales, etc.), sino que se flexibiliza y se adapta a las necesidades de información de cada momento. El modelo infográfico del edificio se convierte así en una base de datos capaz de generar gráficos actualizados.

El modelo infográfico generado no es una reproducción de la "cáscara» del edificio sino una abstracción de su materialidad, capaz no sólo de volcar datos físicos y geométricos de sus elementos constructivos, sino también de permitir el análisis de una realidad morfológicamente compleja. El hecho de constituir un modelo masivo lleva implícito el concepto del lleno y el vacío, como herramienta esencial del análisis de la arquitectura.

Ésta última afirmación enlaza con la continuidad de esta investigación, en la que, entre otros aspectos, estamos indagando sobre mecanismos que permitan la adaptación de ese modelo infográfico a arquitecturas no arruinadas en las que primen aspectos relacionados con las características de los paramentos visibles de sus fábricas, su comportamiento estructural y los espacios que aquellas envuelven. Un camino posible sería el de estratificar la naturaleza de los elementos que conforman el modelo, de manera que estuviera compuestos no sólo de un único estrato masivo sino también de estratos superficiales y espaciales cuyas entidades puedan ofrecer y contener otro tipo de datos. De esta forma se potenciarían aún más el conocimiento del edificio mediante la lectura de sus paramentos o el análisis de sus características espaciales y funcionales.

Por otro lado, en referencia al modelado de los elementos masivos, la investigación debe encaminarse a flexibilizar los sistemas utilizados para acondicionarlos a las características de la arquitectura. En esta experiencia, el modelado de los elementos más degradados ha sido una tarea bastante ardua debido a la irregularidad de su forma. Es ahí donde otras tecnologías de levantamiento como el escáner láser jugarán un papel importante mediante su implementación con aplicaciones que permitan automatizar el modelado de elementos complejos a partir de la nube de puntos generada, reduciendo considerablemente el tiempo empleado y aumentando la precisión métrica y formal del resultado.

Respecto a la interrelación de datos, este trabajo sólo ha pretendido ser un punto de partida en la indagación sobre las posibilidades que podría ofrecer un sistema completo de información y gestión del patrimonio arquitectónico apoyado en una base gráfica similar a la confeccionada para la casa de Hylas. Se ha partido de la aplicación de una serie de conceptos, relacionados con la práctica del levantamiento, el análisis y la intervención en 
el patrimonio construido, en la «fabricación» de una herramienta que, basada en aplicaciones comerciales de uso cotidiano en el ámbito de la arquitectura y la arqueología, facilite la labor de investigadores, profesionales y funcionarios que desarrollen su trabajo en este ámbito. Se ha conseguido vincular un modelo infográfico tridimensional con una base de datos externa produciendo un flujo de información clasificada y actualizada en dos direcciones. Aunque en este trabajo se ha desarrollado un sistema experimental basado en un software muy concreto, la potencialidad demostrada nos permite ser optimistas en cuanto a sus posibles aplicaciones en el ámbito patrimonial, ya sea de forma autónoma en el caso de arquitecturas exentas o en combinación con otros sistemas, como el SIG, en el caso de conjuntos monumentales o arqueológicos como el que en este caso ha servido de referencia. En ese sentido, el desarrollo de esta etapa del proceso dio pie a reflexiones acerca de una serie de aspectos que son cruciales en la investigación sobre futuros sistemas integrados de información y gestión del patrimonio arquitectónico:

- Métodos de clasificación y jerarquización de la información contenida en el sistema.

- Naturaleza de los mecanismos de interrelación entre el modelo gráfico y la base de datos.

- Posibilidades derivadas de la exportación de datos a otras aplicaciones informáticas para la obtención de informes, mediciones, valoraciones, catalogaciones, inventarios, etc., en el ámbito de la gestión del monumento o para la generación de documentación útil en el ámbito de la difusión.

- Capacidad de interactividad y apertura del sistema a los posibles agentes involucrados en el ámbito patrimonial.

- Posibilidades de actualización y adaptación del sistema a un proceso continuo de investigación e intervención sobre el objeto arquitectónico.

\section{Bibliografía}

AA.VV.: Catedral de Santa María Vitoria-Gasteiz. Plan Director de Restauración (3 vols.). Vitoria, Diputación Foral de Álava, 1999.

Almagro Vidal, A. El concepto de espacio en la arquitectura palatina andalusí. Un análisis perceptivo a través de la infografía. CSIC. Madrid. 2008.

Caballos, A., Marín, J. y Rodríguez, J.M. Itálica Arqueológica. Ediciones Especiales $\mathrm{n}^{\circ} 25$. Secretariado de Publicaciones de la Universidad de Sevilla, Fundación El Monte, Consejería de Cultura de la Junta de Andalucía. Sevilla. 1999.

Catalá, J.M. La imagen compleja. La fenomenología de las imágenes en la era de la cultura visual. UAB. Servei de publicaciones. Barcelona. 2005.

Corzo Sánchez, R. Organización del territorio y evolución urbana en Itálica. Itálica (Santiponce, Sevilla) Actas de las Primeras Jornadas sobre Excavaciones Arqueológicas en Itálica. Excavaciones Arqueológicas en España 121, 299319. 1982.

Esteban, J. Constantes y procesos determinantes en la conservación del patrimonio arquitectónico español (1844-1900). Actas del II Seminario Teoría e Historia de la Restauración en España 1844-1900 (Valencia 1997). VII Máster en Conservación del Patrimonio Arquitectónico. Universidad Politécnica de Valencia, 2-33. 2007.

Fernández Gómez, F. Las excavaciones de Itálica y Don Demetrio de los Ríos a través de sus escritos. Obra Social y Cultural Cajasur. Córdoba. 1998.

Fernández Martín, J.J., et al. «Modelos ampliados digitales para planificación y gestión de intervenciones sobre edificios y entornos urbanos complejos». ACE@ Vol.2, núm. 4, junio 2007.

Fernández Martín, J.J, San José Alonso, J. El sistema de información del patrimonio SIP. Apuntes sobre la gestión y el soporte de datos. Actas del VIII Congreso de Expresión Gráfica Arquitectónica. (2000), pp. 311-316. 2000.

García Y Bellido, A. (ed. Or. 1960). Andalucía Monumental: Itálica. Ed. Andaluzas Unidas. 1985.

Goitia, A. Restituir, redibujar, aventurar. Estrategias para documentar tres puertas monumentales de Madrid. Revista EGA 15, 74-83. 2010.

Jiménez A. y Pinto F. Levantamiento y Análisis de Edificios. Tradición y futuro. Textos de doctorado. IUCC. Universidad de Sevilla. Sevilla. 48. 2003.

Lerma, J.L., Cabrelles, M., Seguí, A. y Navarro, S. Aplicación de la fotogrametría terrestre al levantamiento de alzados de edificios singulares. Revista PH no77. Instituto Andaluz del Patrimonio Histórico, 127-129. 2011.

Luzón, J.M. La Itálica de Adriano. En Arte Hispalense no 9. Diputación de Sevilla. Sevilla. 1979.

Mañana-Borrazas, P., Rodríguez, A. y Blanco, R. Una experiencia en la aplicación del Láser Escáner $3 D$ a los procesos de documentación y análisis del patrimonio construido: su aplicación a Santa Eulalia de Bóveda (Lugo) y San Fiz de Solovio (Santiago de Compostela). Revista Arqueología de la arquitectura No5, 15-32. 2008.

Mañas Romero, I. Arquitectura doméstica en Itálica. Itálica. Ciudades del Imperio. Colección L'Erma de Bretschneider, A. Caballos Rufino (coord.), 77-82, Sevilla. 2010.

Mata Carriazo, J. de. Itálica. Programa y Guía del VIII Congreso Arqueológico Nacional. Sevilla-Málaga. 1963.

Mesa Gisbert, A., Regot, J. Núñez, M.A. y Buil, F. Toma de datos, análisis y técnicas de modelado paralel control métrico de elementos en Selinunte». UPC. 2006.

Mesa Gisbert, A., Regot, J. Núñez, M.A. y Buil, F. Métodos y procesos para el Levantamiento de reconstrucción tridimensional gráfica de elementos del patrimonio cultural. La iglesia de Sant Sever de Barcelona. En revista EGA 14, 82-89. 2009.

Navarro, P., Cabanes, J.L. Edición avanzada de fotomodelos de edificios. Revista EGA 14, 68-73. 2009.

Navarro, P., Herráez, J., Mora, A., Barros, H. y Denia, J.L. Aplicaciones de la tecnología de digitalización tridimensional por la coordinación de monumentos históricos del instituto nacional de arqueología e historia (INAH) en México DF. (2009 y 2010). Revista EGA 17, 42-53. 2011.

Rodríguez De Guzmán Sánchez, S. (coordinadora), Plan Director del Conjunto Arqueológico de Itálica. Documento de Avance. (Versión junio 2011). Consejería de Cultura, Junta de Andalucía. Málaga. 2011.

Pinto Puerto, F., Guerrero, J.M., Castellano, M., Pastor, F. y Angulo, R. Aplicación de los Sistemas BIM a la Gestión de Conjuntos Arqueológicos: Itálica. I Congreso Nacional de Investigación Aplicada a la Gestión de Edificación (1). Núm. 1. Alicante, España. Publicaciones de la Universidad de Alicante, 116133. 2010.

Pinto Puerto, F., Guerrero, J.M., Castellano, M., Pastor, F. y Angulo, R. Construcción de una base gráfica activa para el conjunto arqueológico de Itálica. Revista PH no77. Instituto Andaluz del Patrimonio Histórico, 116-119. 2011.

San José, J. La réplica en el contexto de la gestión del patrimonio inmueble. Tres capillas sixtinas. Revista EGA 17, 104-113. 2011.

Vale, J.M. y Rodríguez, A. Características básicas de los modelos tridimensionales de elementos históricos. Revista $\mathrm{PH} \mathrm{n}^{\mathrm{o}} 77$. Instituto Andaluz del Patrimonio Histórico, 145-148. 2011.

Recibido: 21 de diciembre de 2011 Aceptado: 25 de septiembre de 2012 